\title{
“Let's Have At It!" Conversations with EDM Producers Kate Simko and DJ Denise
}

\author{
REBEKAH FARRUGIA \\ OAKLAND UNIVERSITY
}

conversations

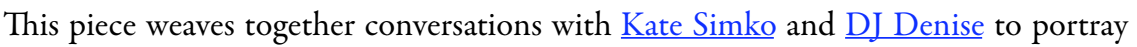
the two different, yet overlapping paths they have taken to establish themselves as electronic dance music (EDM) producers. Both women are pioneers in their own right. Simko is best known as Spectral Sounds' "first lady of techno". DJ Denise, who first gained popularity as a San Francisco Bay Area DJ, has since become a prolific producer and the founder of the label Mizomo Music, which specializes in various forms of house music. Relying on personal interviews with both producers, this essay describes their experiences in order to highlight their different approaches to music production and distribution. Additionally, it considers how the increased accessibility and user friendliness of digital music production/distribution has changed the conditions for both women and men in the EDM business.

It is just after noon on a spring day when I arrive at the trendy café on Chicago's North side where Kate Simko and I have agreed to meet. ${ }^{1}$ I am eager to learn about Simko's EDM trajectory, particularly what has enabled her to succeed in an environment that most women continue to experience as impermeable. How does a woman move from expressing an interest in producing EDM to releasing tracks on an internationally recognized record label, and why aren't there more of them doing so? After all, there are numerous female DJs dedicated to spinning EDM, yet tracks produced by women remain too few and far between.

The gendered divisions within dance music culture mimic those found in other popular music genres such as punk and hip hop. In the 1980s, EDM in the US evolved from disco in cities such as Chicago and New York where it was strongly connected to local gay culture and ethnic minorities (Fikentscher 2000: 11); however, by the height of its popularity in the late 1990s it had been co-opted by an industry predominantly run and consumed by white, heterosexual men. Many of them became DJs and producers whom the dance music industry used as marketing tools (Reynolds 1999: 276). By this time DJing had become a competitive sport and producing an even more guarded art form. Simon Reynolds accounts for the "homosocial nature of techno" in the following explanation:

tricks of the trade are passed down from mentors to male acolytes. DJ-ing and samplebased music also go hand in hand with an obsessive 'trainspotter' mentality: the amassing of huge collections of records, the accumulation of exhaustive and arcane information about labels, producers, and auteurs (Reynolds 1999: 274).

Dance music's failure to maintain a degree of interest in the US on par with many European countries rendered knowledge about the music and culture esoteric and 
difficult to permeate. In turn, this situation made it especially difficult for women to break into these spaces, especially the production of techno.

I first heard Kate Simko's music on MySpace. Our profiles were linked by one degree of separation. In the past few years she has composed numerous EDM tracks, most of which have been released by Spectral Sounds, the companion label to Ghostly International, an independent record label based in Ann Arbor, Michigan. Since it was launched in 1999, Ghostly has generated accolades from a range of music and media outlets worldwide, including Rolling Stone, Billboard Magazine and Advertising Age. Spectral Sounds is dedicated to more dance floor-oriented music compared to the ethereal electronic sounds released on Ghostly. A quick glance at the label's list of artists is testament to Simko's atypical success. Of the 21 artists featured, she is the only woman, and hence, has been dubbed as the label's "first lady of techno", a title no doubt intended to honor Simko for her talent and success. While she is not the first woman to produce techno music she was indeed the first - and remains the only signed to the prestigious label. Her status as Spectral's only female artist enables her "first lady" title to also function as public relations material. Not only can Spectral take credit for its anomalous discovery but Simko's presence is an element it can potentially use to differentiate itself from other EDM labels, most of which do not have any women on their rosters. Not only is she one of few women who produce EDM, but her production of "dance floor friendly" beats such as those found on Simko's She Said $\underline{E P}$ and the more recent track "Dublake" make her even more of a rarity. Many women DJs I have interviewed over the years have expressed an interest in producing, a desire that is partly fueled by the scarcity of women-produced, dance floor friendly tracks. Yet, few are able to overcome the technological and social obstacles related to composition and distribution.

Spectral's public relations materials for Simko include a video artist profile hosted on vimeo.com. In it, Simko discusses everything from her earliest musical experiences growing up in Evanston, Illinois, to her future plans. In many ways, the short documentary presents her success and story as straightforward and logical, if not easy. We learn that she grew up in a musical family of middle class stature and was enrolled in piano lessons at the age of six from which time she learned a deep appreciation for music. Though the video's caption bills her as the label's "first lady", its narrative is gender neutral.

During our interview I learn that Simko's first introduction to EDM was as a high school student in Illinois, but it was her exposure to IDM (intelligent dance music) while studying piano as a freshman at the University of Miami, Florida, that sparked her interest in producing. She then had the self-realization that she wanted to make her own music. Simko expressed her deep-rooted determination by saying, "I didn't know how but I was going to try to figure it out and it took a long time". After a year in Miami she transferred to Northwestern University and eventually graduated with a major in digital music production. She explained the arduous process as follows:

I saw that they had a music technology program. I had to audition at the level of a piano major at Northwestern and it's one of the top three piano schools in the US. It took me a year just to prepare for the audition so I started taking classical piano again just to study for my audition. On top of that I had to study classical piano at the level of a freshman performance for one year. There were film students and really creative people who wanted to do stuff and they were like no, you have to be straight up virtuoso to study electronic 
music...That's where I was able to learn, to be nurtured and be given credit in school and have the time and the luxury to be getting credit through Northwestern to figure out how to make electronic music.

During her final year Simko studied abroad in Chile where she expanded her knowledge of Spanish as well as her sonic horizons. While in Chile she began experimenting with Logic Pro and completed her first album Shapes of Summer with Chilean Andres Bucci under the moniker Detalles. The German label Traum Schallplatten released the collection in 2003. She explained the experience of learning to use the software:

That was 2001. At the time it wasn't user friendly at all. It was much harder then. Logic 7 with Apple is much easier. The manual was a horrible translation from German to English. It was rough. I'm not gonna lie. I was there with the thick manual reading the paragraph over and over again. I couldn't figure out how to start really.

In 2005, her first solo track "Houston Skyline" - a Philip Glass remix - was released on the compilation album Glass Cuts: Philip Glass Remixes. This success motivated Simko to dedicate as much time as possible to producing while working as a real estate agent but not without some internal struggles. "Honesty at the point Ghostly said yes to me there was definitely a point in my head where I was like well maybe people just don't like this music I'm doing. I knew in my heart I wasn't there yet and didn't know if I could tweak what I was doing into a dance floor realm. It was definitely hard". Since 2005, Simko's discography has grown to include six solo tracks plus three collaborative releases all on well known independent EDM labels, as well as seven remixes of other artists' music. She has had two of her tracks remixed by well-established techno producers. In 2008, Simko toured her beats as she headlined a six-city tour sponsored by Spectral that included stops in Montreal, Los Angeles and Chicago. Besides compiling beats for the dance floor, Simko has also scored the soundtrack to the science documentary The Atom Smashers which Spectral has since made available as the digital release Music from the Atom Smashers.

It is important to note that the demanding process involved in becoming a major in a music technology program such as the one from which Simko graduated is out of reach for most individuals, men and women alike, who have not had extensive musical training prior to college. Additionally, the opportunities to learn to produce is even more limited for women who have less access to the informal, male-centered social networks through which tricks of the trade are often passed along.

While Simko was busy developing her production skills in Chicago, DJ Denise was exercising her DJ capital in the San Francisco Bay Area for similar purposes. DJ Denise began her DJ career in Berkeley, California, in 1998. When we first met in 2003, she had recently decided that producing was her next logical career move since her high profile DJ career had already led to valuable networking opportunities with producers. For Denise, access to others with gear and knowledge proved invaluable. "I had a very strong network of DJ friends and producers. I was able to pick other people's brains, ask questions, [and] learn and exchange tips".2 In particular, she has commented on the collaborative process she experienced with her first music partner Aleks. "He would do the actual engineering of the song while I sat beside him and made comments and suggestions. He would teach me as we went along with each track". Denise and Aleks completed the track "Machines" in December 2003. "Toward the end of 2004, I received help from two other producer friends of mine who passed 
on some software for producing (Cubase 2.0 and a slew of VSTs, which are essentially computer-based synthesizers), and once I had the software set up on my computer, I started making electronic music on my own". ${ }^{3}$ Denise completed her first solo project, the trance track "Simple Reform", in January 2005. By the end of that year she established her label, Mizumo Music. To further enhance her production skills Denise enrolled in music production classes at Diablo Valley College where she earned a certificate in Recording Arts a year and a half later. Since January 2006, she has released over seventy original collaborative and solo tracks and remixes.

The accomplishments and processes described above highlight the ways in which both DJ Denise and Kate Simko have broken through EDM's gender barriers as producers; however, as women their success sometimes depends on proving more than just their artistic merit. The processes involved require them to actively interact with men at every level - from learning to create EDM, to dealing with equipment store personnel, record label management and other artists. Reflecting on her sex and gender Simko explained her experiences by saying:

I've never in my life used it as an advantage but I can see how it can be an advantage, being a woman. I think so. I think that if you're good it's not a disadvantage. If you're unknown, maybe people won't take you seriously. You have to prove yourself coolness wise. Hanging out, I've had to prove myself way harder than guys do. Some guys just don't know how to hang out with me. It took a long time for me to prove myself. I feel like guys are a lot less prone to ripping on other guy DJs, [it's] much easier to rip on a girl like, dude she sucks. You feel like you have to be $200 \%$ prepared for every situation. If you're a guy you can just roll in [to an equipment store] and you know you can ask and say hey what kind of drum machines do you have and they won't be patronizing at all. They'll show you all the drum machines. As a woman, all the time you feel like you want to be prepared. At the same time, why not? If every guy was $200 \%$ prepared maybe there wouldn't be so many horrible guy DJs.

At first Simko downplays the impact that gendered social constructions have had on her career because she has experienced success in despite of them, but as she continues to reflect on her experiences she notes having had to prove herself "way harder than guys do".

Sadly, this situation is not unique to EDM, but the degree to which EDM remains a male-centered enterprise does exacerbate the matter. Women's relationships with independent record labels and the problems female artists encounter at the distribution level in particular have been well documented. As Keith Negus indicates, "the 'intuitive' assumptions that staff make when acquiring the most suitable new artists and pieces of music are based on beliefs informed by a series of gender, class and racialized divisions" (1999: 21). Fortunately for Simko, her hard work, dedication and knowledge led to a now long-standing relationship with her primary record label, Spectral Sounds.

For DJ Denise, starting a record label enabled her to move into a position of power in the industry. As of December 2009, Mizumo Music has 39 releases featuring 100 artists; yet even though the label is female-owned it still has the typical roster of white men, which in itself demonstrates the scarcity of female producers. One way to bring women to the label has been through collaboration between Denise and other female DJs. The track "Hearsay (Part I)" is the work of DRC + DJ Denise. Denise also partnered with Elz on the track "Get Back in the Groove" (DJ Denise + Elz Remix) 
on Mizumo Music's release by Homero Esponosa and DJ Denise titled Bridging the Gap E.P. 2008-2009 Remixes.

The impact of these collaborative production projects should not be under estimated as similar strategies among women DJs over the years have proven successful. In 1996, in response to what they felt was negative bias from other DJs based on their sex and gender at the time a handful of women formed the women-centered DJ collective SisterSF. ${ }^{4}$ By 2004 , Sister had expanded its presence nationwide with chapters in Portland, Oregon, Denver, Colorado and New York City (SisterNYC). While these collectives are no longer as dynamic as they once were, they actively promoted the talent of female DJs for over a decade and served as role models for girls and women by opening up the possibility that they too could become DJs. An increase in women-centered music making environments would similarly provide the social and cultural access to technology and knowledge needed to increase production opportunities for women.

Although historically collaboration has been important to women in EDM, technological innovations present new opportunities for both collective activity and individual success. The ubiquity of the Internet and other digital technologies are enabling female media artists to do two important things that should continue to be encouraged. The first is networking online via social network sites such as Facebook and MySpace. Second, the convergence of video, audio and other digital media technologies have created new distribution networks enabling artists to bypass traditional record labels - and the politics implicit in these institutions - and independently release their music into the ether. Kate Simko described the importance of social network sites to her role as an EDM artist by saying:

[The Internet] has helped a lot. A lot of people do [contact me via Internet]. It's really cool. Over the weekend I met someone from Berlin. I can so easily can go onto MySpace and be like, hey nice to meet you. Now we're in touch. If I want to I can send him music or whatever. Otherwise do you take the time and effort to try to figure out who knows him and get his email and really go out of your way? MySpace is a really benign way to be in contact or have someone contact you and not feel like your space is invaded.

DJ Denise spoke to the development of new distribution networks and how the Internet and MP3 technologies have been instrumental to her success. The description of her process is insightful.

I initially set up relationships with labels by good old fashion guerrilla tactics. I went on Beatport.com, went to the genre of labels that I wanted to work with, copied down about 1,200 different label names, and started searching online (via Google) for contact names \& emails. (Granted, I only got about 500 of those contacts successfully, and I still have about 700 to go! When I first contacted some of these labels (usually by Myspace), I asked for their contact email $\&$ also mentioned that I was available for remix work. I was hired on the spot for about 10 jobs simply by asking - again, however, based on royalty agreements (usually 50\%). Now, when I am shopping out an original track, I send an mp3 link to the track to this list of 500 labels, and without fail, I get at least 10-15 replies from labels that are interested in signing the track?

In 2002, NPR cultural correspondent Rick Karr presented a six-part series on how technology has changed popular music. Karr quotes famous Chicago recording engineer and producer Steve Albini as saying that the rapidly falling price of professional recording equipment has led to "the triumph of the amateurs" as individuals can 
now self-produce music on digital work stations and distribute their material online. In other words, the ability to create praiseworthy music is no longer confined to artists at the mercy of record labels with sizeable budgets for studio time, marketing and distribution. The increasing mainstream success of bedroom musicians at the end of the oughts continued to prove this point. Laptop artists such as Gregg Gillis, aka Girl Talk, are destabilizing the notion that the "studio hero" is more knowledgeable or prestigious than his or her DIY counterparts. Primarily a sampling artist, Girl Talk's success has enabled Gillis to quit his day job as an engineer and pursue music as a career. His fourth album, Feed the Animals received four out of five stars in Rolling Stone (Hoard 2008) and ranked fourth on Time magazine's Top 10 Albums of 2008 (Tyrangiel 2008).

As access to computers and music production software persists, the boundaries between studio and bedroom producers continue to dissolve. In addition to the economic factors involved, traditionally the social boundaries rooted in technical knowledge and language have exacerbated studio labor divisions (Porcello 1991) and worked to keep both men and women outside this space for fear that demystifying the production process could damage the studio's symbolic and/or use value (Meintjes 2003; Farrugia and Swiss 2008). Presently, countless online forums, websites and magazines - most notably Remix - feature reviews, interviews and tutorials as part of their growing collections of information for electronic musicians.

The possibilities brought on by these changes have repeatedly been hailed as democratizing, empowering, and valuable for all potential music producers, but only recently have we begun to witness women at the center of these triumphs. If one considers the success and productivity of Kate Simko and DJ Denise in tandem with the increase of digital networks and technologies, a future of dance floor friendly beats produced by women becomes much more than hopeful thinking. In DJ Denise's words: "I don't think in this day and age we as women can feel intimidated by technology — as with anything in life, you just have to stand up to it \& say 'Let's have at it!'”

\section{Acknowledgments}

The author wishes to thank DJ Denise and Kate Simko for their time and willingness to be interviewed, as well as Kathleen Battles for her astute comments during the preparation of this manuscript.

\section{References}

Farrugia, Rebekah and Thom Swiss. 2008. "Producing Producers: Women and Electronic/ Dance Music”. Current Musicology 86: 79-100.

Fikentscher, Kai. 2000. "You Better Work!" Underground Dance Music in New York City. Hanover, NH: Wesleyan University Press.

Hoard, Christian. "Feed the Animals by Girl Talk". Rolling Stone Magazine, July 2008. <http://www.rollingstone.com/reviews/album/21457036/review/21463543/feed the animal $>$ (accessed 28 March 2010).

Meintjes, Louise. 2003. Sound of Africa! Making Music Zulu in a South African Studio. Durham, NC: Duke University Press. 
Negus, Keith. 1999. Music Genres and Corporate Cultures. New York: Routledge.

Porcello, Tom. 1991. "Speaking of Sound: Language and the Professionalization of SoundRecording Engineers". Social Studies of Science 34 (5): 733-758.

Reynolds, Simon. 1999. Generation Ecstasy: Into the World of Techno and Rave Culture. New York: Routledge.

Tyrangiel, Josh. "4. Feed the Animals by Girl Talk - The Top 10 Everything of 2008". Time Magazine, December 2008. <http://www.time.com/time/specials/packages/article/ $\underline{0,28804,1855948 \_1864324 \_1864335,00 . h t m l>}$ (accessed 29 March 2010).

\section{Mediography}

Detalles. Andreas Bucc + Kate Simko. 2003. Shapes of Summer. Traum Schallplatten (CD): Traum CD12. http://www.discogs.com/release/139352

DJ Denise + Elz. 2009. Get Back in the Groove from Bridging the Gap EP. 2008-2009 Remixes. Mizumo Music (mp3): MIZ008D. http://www.mizumomusic.com/releases/releases.html

DRC + DJ Denise. 2009. Hearsay. Mizumo Music (mp3): MIZ038. http://www.mizumomusic.com/releases/releases.html

Kate Simko. 2005. Houston Skyline from Glass Cuts (Philip Glass: Remixed). Orange Mountain Music (CD): OMM0023. http://www.discogs.com/release/876058

Kate Simko. 2008. She Said EP. Spectral Sound (12-inch): SPC57. http://www.discogs.com/release/1286778

Kate Simko. 2009. Music from the Atom Smashers. Ghostly International (mp3): GIDG17. http://www.discogs.com/release/1950642

Kate Simko. 2009. Dublake. Ghostly International (mp3): catalog number not available. http://static.ghostly.com/media/mp3/full/simko dublake 9918.mp3

Brown, Clayton and Long Ross, Monica, and Suprenant, Andrew (dir.). 2007. The Atom Smashers. USA. 137 Films. http://www.137films.org/films/theatomsmashers/

\section{Author Biography}

Rebekah Farrugia is an Assistant Professor of Media Studies in the Department of Communication and Journalism at Oakland University whose research interests lie at the intersection of gender, technology and popular music. Her work has most recently been published in Current Musicology, Feminist Media Studies and Popular Music and Society.

\section{Notes}

1 Kate Simko, interview with the author (Dolce Casa, Chicago), 29 May 2008.

2 DJ Denise, interview with the author (42 Dutton Ave, San Leandro, CA), 8 July 2003.

3 DJ Denise, email to author, 13 November 2008.

4 Annie Shaw, aka XJS, interview with the author (Skylark Bar, San Francisco), 22 July 2003.

5 DJ Denise, email to author, 13 November 2008.

6 DJ Denise, email to author, 13 November 2008. 